\title{
Semi-analytical solution for consolidation of vertical drain to un- saturated soils considering well resistance and smear effect un- der time-varying loadings
}

\author{
Aifang Qin*, Lianghua Jiang, Linzhong Li and Xinhao Li \\ Department of Civil Engineering, Shanghai University, Shanghai 200444, China
}

\begin{abstract}
In this paper, based on equal-strain assumption a semi-analytical solution, considering well resistance, smear effect and time-varying loading, is deduced for radial consolidation aided by vertical drain (VD) to unsaturated soils. Firstly, by employing the general integration, Laplace transform, decoupling methods and numerical inverse Laplace transform, the semi-analytical solution in the time domain is obtained. Then, its validity is verified by the special cases of the proposed solution under instantaneous loading. Finally, the case analysis show that the dissipation of excess pore pressures is accelerated with the decrease of smear coefficients $\left(\alpha_{\mathrm{a}}\right.$ or $\left.\alpha_{\mathrm{w}}\right)$ or well resistance factors $\left(G_{\mathrm{a}}\right.$ or $\left.G_{\mathrm{w}}\right)$. In addition, when the well resistance factor is less than 1, the barrier of VD material to flow can be ignored. Furthermore, a smaller value of the loading frequency of cyclic loading, the bigger the amplitude, and the less fluctuation period in the dissipation rates. Moreover, the current solution can analyse the consolidation characteristics of unsaturated soils with VDs under arbitrary time-varying loadings, including cyclic loadings.
\end{abstract}

\section{Introduction}

VDs (sand columns or prefabricated vertical drains), combined with preloading, are often used to enhance the strength and stiffness of soft soils in highway and railway subgrade. In unsaturated soils, the widely accepted consolidation theory is the two stress-state variables theory [1]. On this foundation, the solution of $1 \mathrm{D}$ consolidation to unsaturated soils is obtained with the semi-analytical method [2]. In addition, for the study of axisymmetric consolidation to unsaturated soils, Qin et al. [3] adopted the mathematical methods of Laplace transform and Bessel function, and acquired the semi-analytical solution; Zhou [4] achieved the explicit solution with differential quadrature method (DQM). Ho and Fatahi [5] produced the analytical solution for consolidation of VDs to unsaturated soils by means of the Laplace transform technique and separation of variables. Recently, using the equalstrain assumption, some parameters or factors affecting the consolidation to unsaturated soils by VDs under instantaneous loading like smear effects, drainage condition, radius of drains and ratio of radius, as well as well resistance and hydraulic conductivity ratio are analyzed [6, 7]. Some attempts has been made in the theoretical study of axisymmetric consolidation to unsaturated soils. The consolidation characteristics to unsaturated soils with VDs, however, has not been analysed when considering well resistance, smear effect and time-varying loadings simultaneously.

This paper explores the equal-strain consolidation characteristics of unsaturated soils with arbitrary time- varying loadings. Two coupled governing equations of excess pore pressures are integrated and combined with the boundary conditions. Based on the decoupling technology and Laplace transform, the coupled non-homogeneous partial differential equations are transformed into a pair of ordinary differential equations (ODEs), which are easily solved with the boundary conditions in the Laplace domain. Then, the semi-analytical solution is obtained by using the numerical inverse Laplace transform with Crump's methods. By comparing with the solution for consolidation aided by VDs to unsaturated soils under equal-strain and free-strain assumption, the validity of the proposed solution is proved. Finally, exponential loading and sinusoidal cyclic loading are utilised to present the consolidation characteristics of unsaturated soils improved with VDs. Other than that, the consolidation characteristics with different smear effect, well resistance and loading frequency are studied by numerical examples. It is readily apparent that the current solution derived in this paper is more effective and widely applicable.

\section{Mathematical model}

\subsection{Governing Equations}

Figure 1 illustrates the details of the typical VD within a smear zone and an undisturbed unsaturated soils area. Including the thickness of the unsaturated soils layer $H$ and the radius of VD $r_{\mathrm{w}} ; r_{\mathrm{e}}$ and $r_{\mathrm{s}}$ represent the radii of the influence area and smear zone of the VD system, respectively. In addition, the top $(z=0)$ boundary of unsaturated

\footnotetext{
* Corresponding author: qinaifang@shu.edu.cn
} 
soils layer is pervious. The bottom (i.e. $z=H$ ) and outer (i.e. $r=r_{\mathrm{e}}$ ) boundary of VD system are both impermeable to air and water. Over and above that, the radial coefficients of permeability to air and water for unsaturated soil in influence area (smear zone) are $k_{\mathrm{a}}$ and $k_{\mathrm{w}}\left(k_{\mathrm{as}}\right.$ and $\left.k_{\mathrm{ws}}\right)$,

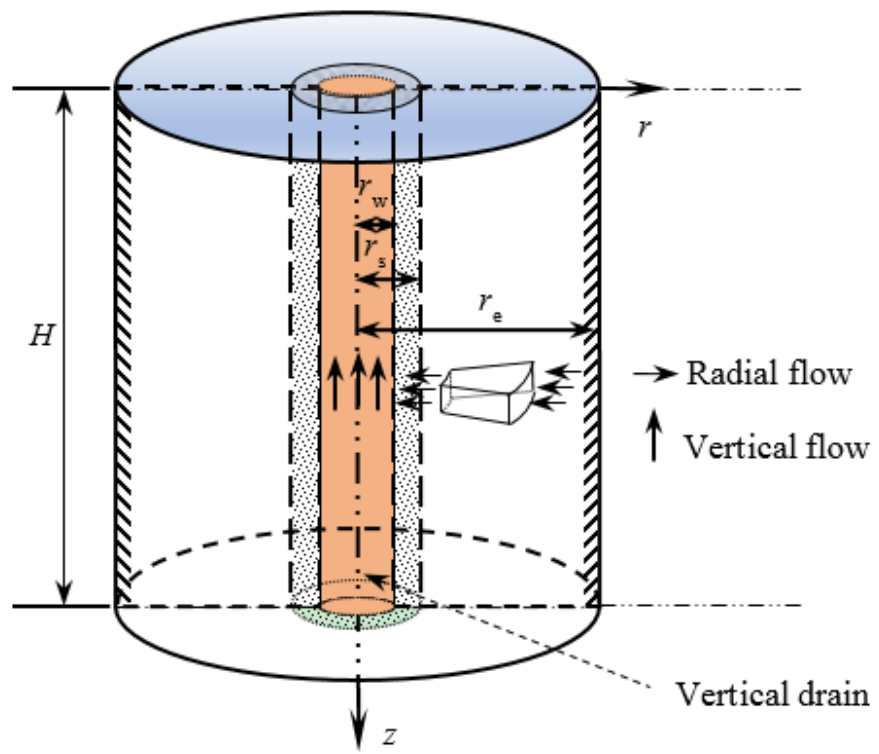

respectively. $k_{\mathrm{aw}}$ and $k_{\mathrm{ww}}$ are the air and water permeability coefficients of the material of VD. $t$ is the consolidation time, and $q(t)$ is a time-varying loading, which applied vertically on the surface of the unsaturated soil layer.

Figure 1. Consolidation modeling of unsaturated soils by vertical drains considering well resistance and smear effect under equalstrain assumption

The main research hypothesis are same as those applied to equal-strain consolidation to unsaturated soils with VDs [6]. In fact, the coefficients of permeability related to the change of air and water phases throughout the consolidation process of unsaturated soils are functions of stress state. Assuming these parameters, however, are constant with the assumption of small strain, it is helpful to solve the governing equation of VD-improved consolidation to unsaturated soils, so as to analyze the consolidation characteristics of unsaturated soils under complex conditions.

According to the axisymmetric consolidation theory of unsaturated soils under the assumption of equal-strain [6, 7], the governing equations are expressed as follows:

$$
\begin{aligned}
& \frac{\partial \bar{u}_{\mathrm{a}}}{\partial t}=-C_{\mathrm{a}} \frac{\partial \bar{u}_{\mathrm{w}}}{\partial t}-C_{\mathrm{v}}^{\mathrm{a}}\left(\frac{\partial^{2} u_{\mathrm{a}}}{\partial r^{2}}+\frac{1}{r} \frac{\partial u_{\mathrm{a}}}{\partial r}\right)+C_{\mathrm{q}}^{\mathrm{a}} \frac{\mathrm{d} q}{\mathrm{~d} t} \\
& \frac{\partial \bar{u}_{\mathrm{w}}}{\partial t}=-C_{\mathrm{w}} \frac{\partial \bar{u}_{\mathrm{a}}}{\partial t}-C_{\mathrm{v}}^{\mathrm{w}}\left(\frac{\partial^{2} u_{\mathrm{w}}}{\partial r^{2}}+\frac{1}{r} \frac{\partial u_{\mathrm{w}}}{\partial r}\right)+C_{\mathrm{q}}^{\mathrm{w}} \frac{\mathrm{d} q}{\mathrm{~d} t}
\end{aligned}
$$

in which

$$
\begin{aligned}
& \bar{u}_{\mathrm{a}}=\frac{1}{\pi\left(r_{\mathrm{e}}^{2}-r_{\mathrm{w}}^{2}\right)}\left(\int_{r_{\mathrm{w}}}^{r_{\mathrm{s}}} u_{\mathrm{as}} 2 \pi r d r+\int_{r_{\mathrm{s}}}^{r_{\mathrm{e}}} u_{\mathrm{a}} 2 \pi r d r\right), \\
& \bar{u}_{\mathrm{w}}=\frac{1}{\pi\left(r_{\mathrm{e}}^{2}-r_{\mathrm{w}}^{2}\right)}\left(\int_{r_{\mathrm{w}}}^{r_{\mathrm{s}}} u_{\mathrm{ws}} 2 \pi r d r+\int_{r_{\mathrm{s}}}^{r_{\mathrm{e}}} u_{\mathrm{w}} 2 \pi r d r\right)
\end{aligned}
$$

where

$$
\begin{aligned}
& C_{\mathrm{a}}=m_{2}^{\mathrm{a}}\left[m_{1 \mathrm{k}}^{\mathrm{a}}-m_{2}^{\mathrm{a}}-u_{\mathrm{atm}} n_{0}\left(1-s_{\mathrm{r} 0}\right) /\left(\overline{\bar{u}}_{\mathrm{a}}^{0}\right)^{2}\right]^{-1}, \\
& C_{\mathrm{v}}^{\mathrm{a}}=k_{\mathrm{a}} R T\left\{g \overline{\bar{u}}_{\mathrm{a}}^{0} M\left[m_{1 \mathrm{k}}^{\mathrm{a}}-m_{2}^{\mathrm{a}}-u_{\mathrm{atm}} n_{0}\left(1-s_{\mathrm{r} 0}\right) /\left(\overline{\bar{u}}_{\mathrm{a}}^{0}\right)^{2}\right]\right\}^{-1}
\end{aligned}
$$

$$
\begin{aligned}
& C_{\mathrm{q}}^{\mathrm{a}}=m_{1 \mathrm{k}}^{\mathrm{a}}\left[m_{1 \mathrm{k}}^{\mathrm{a}}-m_{2}^{\mathrm{a}}-u_{\mathrm{atm}} n_{0}\left(1-s_{\mathrm{r} 0}\right) /\left(\overline{\bar{u}}_{\mathrm{a}}^{0}\right)^{2}\right]^{-1}, \\
& C_{\mathrm{w}}=\left(m_{1 \mathrm{k}}^{\mathrm{w}}-m_{2}^{\mathrm{w}}\right) / m_{2}^{\mathrm{w}}, \quad C_{\mathrm{v}}^{\mathrm{w}}=k_{\mathrm{w}} / \gamma_{\mathrm{w}} m_{2}^{\mathrm{w}}, \\
& C_{\mathrm{q}}^{\mathrm{w}}=m_{1 \mathrm{k}}^{\mathrm{w}} / m_{2}^{\mathrm{w}} .
\end{aligned}
$$

$\overline{\bar{u}}_{\mathrm{a}}\left(\bar{u}_{\mathrm{a}}+u_{\mathrm{atm}}\right)$ is the absolute average excess pore-air pressure, and $u_{\mathrm{atm}}$ is the atmospheric pressure. $\overline{\bar{u}}_{\mathrm{a}}^{0}$ is the initial value of $\overline{\bar{u}}_{\mathrm{a}} \cdot \bar{u}_{\mathrm{a}}$ and $\bar{u}_{\mathrm{w}}$ are the average excess pore-air and pore-water pressures $(\mathrm{kPa})$, respectively. $u_{\mathrm{a}}$ and $u_{\mathrm{w}}\left(u_{\text {as }}\right.$ and $\left.u_{\text {ws }}\right)$ mean excess pore-air and pore-water pressures in the influence area (smear zone), respectively. $m_{1 \mathrm{k}}^{\mathrm{a}}$ and $m_{1 \mathrm{k}}^{\mathrm{w}}$ are the coefficient of air and water volume change in respect of the change in net normal stress, respectively. $m_{2}^{\mathrm{a}}$ and $m_{2}^{\mathrm{w}}$ are the coefficient of air and water volume change in respect of the change in the matric suction, respectively. $n_{0}$ and $S_{\mathrm{r} 0}$ are the initial porosity and initial degree of saturation, respectively. $M$ is the molecular mass of air $\left(0.02895 \mathrm{~kg} \cdot \mathrm{mol}^{-1}\right) . R$ is the molar gas constant $\left(8.314 \mathrm{~J} \cdot \mathrm{mol}^{-1} \cdot \mathrm{K}^{-1}\right)$, and $T\left(t_{0}+273\right)$ is the absolute temperature. $t_{0}$ is the ambient temperature $\left(20^{\circ} \mathrm{C}\right) . g$ is the gravitational acceleration $\left(9.81 \mathrm{~m} / \mathrm{s}^{-2}\right)$, and $\gamma_{\mathrm{w}}$ is the water unit weight $\left(9.81 \mathrm{kN} \cdot \mathrm{m}^{-3}\right)$.

\subsection{Initial and boundary conditions}

In this paper, it is assumed that the initial excess pore pressures is rectangular along the depth. Thus:

$$
u_{\mathrm{a}}(r, z, 0)=u_{\mathrm{a}}^{0}, u_{\mathrm{w}}(r, z, 0)=u_{\mathrm{w}}^{0}
$$

As shown in figure 1 , the boundary conditions are expressed as followed: 


$$
\begin{gathered}
u_{\mathrm{a}, \mathrm{r}}\left(r_{\mathrm{e}}, z, t\right)=u_{\mathrm{w}, \mathrm{r}}\left(r_{\mathrm{e}}, z, t\right)=0 \\
u_{\mathrm{as}}\left(r_{\mathrm{s}}, z, t\right)=u_{\mathrm{a}}\left(r_{\mathrm{s}}, z, t\right), u_{\mathrm{ws}}\left(r_{\mathrm{s}}, z, t\right)=u_{\mathrm{w}}\left(r_{\mathrm{s}}, z, t\right) \\
u_{\mathrm{as}}\left(r_{\mathrm{w}}, z, t\right)=u_{\mathrm{aw}}(z, t), u_{\mathrm{ws}}\left(r_{\mathrm{w}}, z, t\right)=u_{\mathrm{ww}}(z, t) \\
u_{\mathrm{as}, \mathrm{r}}\left(r_{\mathrm{w}}, z, t\right)+\frac{r_{\mathrm{w}} k_{\mathrm{aw}}}{2 k_{\mathrm{a}}} u_{\mathrm{aw}, \mathrm{z}}(z, t)=0, \\
u_{\mathrm{ws}, \mathrm{r}}\left(r_{\mathrm{w}}, z, t\right)+\frac{r_{\mathrm{w}} k_{\mathrm{ww}}}{2 k_{\mathrm{w}}} u_{\mathrm{ww}, \mathrm{z}}(z, t)=0 \\
u_{\mathrm{aw}}(0, t)=u_{\mathrm{ww}}(0, t)=0 \\
u_{\mathrm{aw}, \mathrm{z}}(H, t)=u_{\mathrm{ww}, z}(H, t)=0
\end{gathered}
$$

\section{Derivation of semi-analytical solu- tion}

\subsection{General semi-analytical solution}

The governing equations (1) can be rearranged and the following equations can be acquired:

$$
\begin{aligned}
& \frac{\partial}{\partial r}\left(r \frac{\partial u_{\mathrm{a}}}{\partial r}\right)=\frac{r}{C_{\mathrm{vr}}^{\mathrm{a}}}\left(-C_{\mathrm{a}} \frac{\partial \bar{u}_{\mathrm{w}}}{\partial t}-\frac{\partial \bar{u}_{\mathrm{a}}}{\partial t}+C_{\mathrm{q}} \frac{\partial q}{\partial t}\right) \\
& \frac{\partial}{\partial r}\left(r \frac{\partial u_{\mathrm{w}}}{\partial r}\right)=\frac{r}{C_{\mathrm{vr}}^{\mathrm{w}}}\left(-C_{\mathrm{w}} \frac{\partial \bar{u}_{\mathrm{a}}}{\partial t}-\frac{\partial \bar{u}_{\mathrm{w}}}{\partial t}+C_{\mathrm{q}}^{\mathrm{w}} \frac{\partial q}{\partial t}\right)
\end{aligned}
$$

By integrating equations (10) and combining with the boundary condition expressed in equation (4) result in:

Domain $r \in\left[r_{\mathrm{w}}, r_{\mathrm{s}}\right]$ :

$$
\begin{aligned}
& \frac{\partial u_{\mathrm{as}}}{\partial r}=-\frac{1}{2}\left(\frac{r_{\mathrm{e}}^{2}-r^{2}}{r}\right) \frac{1}{C_{\mathrm{vs}}^{\mathrm{a}}}\left(-C_{\mathrm{a}} \frac{\partial \bar{u}_{\mathrm{w}}}{\partial t}-\frac{\partial \bar{u}_{\mathrm{a}}}{\partial t}+C_{\mathrm{q}}^{\mathrm{a}} \frac{\partial q}{\partial t}\right) \text { (11a) } \\
& \frac{\partial u_{\mathrm{ws}}}{\partial r}=-\frac{1}{2}\left(\frac{r_{\mathrm{e}}^{2}-r^{2}}{r}\right) \frac{1}{C_{\mathrm{vs}}^{\mathrm{w}}}\left(-C_{\mathrm{w}} \frac{\partial \bar{u}_{\mathrm{a}}}{\partial t}-\frac{\partial \bar{u}_{\mathrm{w}}}{\partial t}+C_{\mathrm{q}}^{\mathrm{w}} \frac{\partial q}{\partial t}\right)
\end{aligned}
$$

Domain $r \in\left[r_{\mathrm{s}}, r_{\mathrm{e}}\right]$ :

$$
\begin{aligned}
& \frac{\partial u_{\mathrm{a}}}{\partial r}=-\frac{1}{2}\left(\frac{r_{\mathrm{e}}^{2}-r^{2}}{r}\right) \frac{1}{C_{\mathrm{v}}^{\mathrm{a}}}\left(-C_{\mathrm{a}} \frac{\partial \bar{u}_{\mathrm{w}}}{\partial t}-\frac{\partial \bar{u}_{\mathrm{a}}}{\partial t}+C_{\mathrm{q}}^{\mathrm{a}} \frac{\partial q}{\partial t}\right) \text { (12a) } \\
& \frac{\partial u_{\mathrm{w}}}{\partial r}=-\frac{1}{2}\left(\frac{r_{\mathrm{e}}^{2}-r^{2}}{r}\right) \frac{1}{C_{\mathrm{v}}^{\mathrm{w}}}\left(-C_{\mathrm{w}} \frac{\partial \bar{u}_{\mathrm{a}}}{\partial t}-\frac{\partial \bar{u}_{\mathrm{w}}}{\partial t}+C_{\mathrm{q}}^{\mathrm{w}} \frac{\partial q}{\partial t}\right) \text { (12b) }
\end{aligned}
$$

The integral of equations (11) and (12) with respect to $r$ are combined with equations (5) and (6).

Domain $r \in\left[r_{\mathrm{w}}, r_{\mathrm{s}}\right]$ :

$u_{\mathrm{as}}=-\frac{1}{2}\left[r_{\mathrm{e}}^{2} \ln \left(\frac{r}{r_{\mathrm{w}}}\right)-\frac{r^{2}-r_{\mathrm{w}}^{2}}{2}\right] \frac{1}{C_{\mathrm{vs}}^{\mathrm{a}}}\left(-C_{\mathrm{a}} \frac{\partial \bar{u}_{\mathrm{w}}}{\partial t}-\frac{\partial \bar{u}_{\mathrm{a}}}{\partial t}+C_{\mathrm{q}}^{\mathrm{a}} \frac{\partial q}{\partial t}\right)+u_{\mathrm{aw}}$ $u_{\mathrm{ws}}=-\frac{1}{2}\left[r_{\mathrm{e}}^{2} \ln \left(\frac{r}{r_{\mathrm{w}}}\right)-\frac{r^{2}-r_{\mathrm{w}}^{2}}{2}\right] \frac{1}{C_{\mathrm{vs}}^{\mathrm{w}}}\left(-C_{\mathrm{w}} \frac{\partial \bar{u}_{\mathrm{a}}}{\partial t}-\frac{\partial \bar{u}_{\mathrm{w}}}{\partial t}+C_{\mathrm{q}}^{\mathrm{w}} \frac{\partial q}{\partial t}\right)+u_{\mathrm{ww}}$

Domain $r \in\left[r_{\mathrm{s}}, r_{\mathrm{e}}\right]$ :

$u_{\mathrm{a}}=-\frac{1}{2}\left[r_{\mathrm{e}}^{2} \ln \left(\frac{r}{r_{\mathrm{s}}}\right)-\frac{r^{2}-r_{\mathrm{s}}^{2}}{2}\right] \frac{1}{C_{\mathrm{v}}^{\mathrm{a}}}\left(-C_{\mathrm{a}} \frac{\partial \bar{u}_{\mathrm{w}}}{\partial t}-\frac{\partial \bar{u}_{\mathrm{a}}}{\partial t}+C_{\mathrm{q}}^{\mathrm{a}} \frac{\partial q}{\partial t}\right)+A$

$u_{\mathrm{w}}=-\frac{1}{2}\left[r_{\mathrm{e}}^{2} \ln \left(\frac{r}{r_{\mathrm{s}}}\right)-\frac{r^{2}-r_{\mathrm{s}}^{2}}{2}\right] \frac{1}{C_{\mathrm{v}}^{\mathrm{w}}}\left(-C_{\mathrm{w}} \frac{\partial \bar{u}_{\mathrm{a}}}{\partial t}-\frac{\partial \bar{u}_{\mathrm{w}}}{\partial t}+C_{\mathrm{q}}^{\mathrm{w}} \frac{\partial q}{\partial t}\right)+W$ where $S=\frac{r_{\mathrm{s}}}{r_{\mathrm{w}}}$,

$$
\begin{aligned}
& A=-\frac{1}{2}\left[r_{\mathrm{e}}^{2} \ln S-\frac{r_{\mathrm{s}}^{2}-r_{\mathrm{w}}^{2}}{2}\right] \frac{1}{C_{\mathrm{vs}}^{\mathrm{a}}}\left(-C_{\mathrm{a}} \frac{\partial \bar{u}_{\mathrm{w}}}{\partial t}-\frac{\partial \bar{u}_{\mathrm{a}}}{\partial t}+C_{\mathrm{q}}^{\mathrm{a}} \frac{\partial q}{\partial t}\right)+u_{\mathrm{aw}} \\
& W=-\frac{1}{2}\left[r_{\mathrm{e}}^{2} \ln S-\frac{r_{\mathrm{s}}^{2}-r_{\mathrm{w}}^{2}}{2}\right] \frac{1}{C_{\mathrm{vs}}^{\mathrm{w}}}\left(-C_{\mathrm{w}} \frac{\partial \bar{u}_{\mathrm{a}}}{\partial t}-\frac{\partial \bar{u}_{\mathrm{w}}}{\partial t}+C_{\mathrm{q}}^{\mathrm{w}} \frac{\partial q}{\partial t}\right)+u_{\mathrm{ww}}
\end{aligned}
$$

By introducing equations (13) and (14) into equations (2) leads to:

$$
\begin{aligned}
& \bar{u}_{\mathrm{a}}=\frac{r_{\mathrm{e}}^{2} F_{\mathrm{a}}}{2 C_{\mathrm{v}}^{\mathrm{a}}}\left(\frac{\partial \bar{u}_{\mathrm{a}}}{\partial t}+C_{\mathrm{a}} \frac{\partial \bar{u}_{\mathrm{w}}}{\partial t}-C_{\mathrm{q}} \frac{\partial q}{\partial t}\right)+\frac{2 u_{\mathrm{aw}}\left(S^{2}-1\right)}{N^{2}-1} \\
& \bar{u}_{\mathrm{w}}=\frac{r_{\mathrm{e}}^{2} F_{\mathrm{w}}}{2 C_{\mathrm{v}}^{\mathrm{w}}}\left(\frac{\partial \bar{u}_{\mathrm{w}}}{\partial t}+C_{\mathrm{w}} \frac{\partial \bar{u}_{\mathrm{a}}}{\partial t}-C_{\mathrm{q}}^{\mathrm{w}} \frac{\partial q}{\partial t}\right)+\frac{2 u_{\mathrm{ww}}\left(S^{2}-1\right)}{N^{2}-1}
\end{aligned}
$$

where $\alpha_{\mathrm{a}}$ and $\alpha_{\mathrm{w}}$ are the smear coefficient related to air and water phases, $\alpha_{\mathrm{a}}=k_{\mathrm{a}} / k_{\mathrm{as}}, \alpha_{\mathrm{w}}=k_{\mathrm{w}} / k_{\mathrm{ws}}, N=\frac{r_{\mathrm{e}}}{r_{\mathrm{w}}}$,

$$
\begin{aligned}
& F_{\mathrm{a}}=\frac{N^{2}}{N^{2}-1}\left[\left(\ln \frac{N}{S}-\frac{3}{4}-\frac{S^{4}}{4 N^{4}}+\frac{S^{2}}{N^{2}}\right)+\alpha_{\mathrm{a}}\left(\frac{S^{4}}{4 N^{4}}-\frac{1}{4 N^{4}}-\frac{S^{2}-1}{N^{2}}+\ln S\right)\right] \\
& F_{\mathrm{w}}=\frac{N^{2}}{N^{2}-1}\left[\left(\ln \frac{N}{S}-\frac{3}{4}-\frac{S^{4}}{4 N^{4}}+\frac{S^{2}}{N^{2}}\right)+\alpha_{\mathrm{w}}\left(\frac{S^{4}}{4 N^{4}}-\frac{1}{4 N^{4}}-\frac{S^{2}-1}{N^{2}}+\ln S\right)\right]
\end{aligned}
$$

Equations (15) can be transformed into:

$$
\begin{aligned}
& \bar{u}_{\mathrm{a}}=A_{\mathrm{a}} \frac{\partial \bar{u}_{\mathrm{a}}}{\partial t}+A_{\mathrm{w}} \frac{\partial \bar{u}_{\mathrm{w}}}{\partial t}-A_{\mathrm{q}} \frac{\partial q}{\partial t}+B u_{\mathrm{aw}} \\
& \bar{u}_{\mathrm{w}}=W_{\mathrm{w}} \frac{\partial \bar{u}_{\mathrm{w}}}{\partial t}+W_{\mathrm{a}} \frac{\partial \bar{u}_{\mathrm{a}}}{\partial t}-W_{\mathrm{q}} \frac{\partial q}{\partial t}+B u_{\mathrm{ww}}
\end{aligned}
$$

where $B=\frac{2\left(S^{2}-1\right)}{N^{2}-1}, A_{\mathrm{a}}=\frac{r_{\mathrm{e}}^{2} F_{\mathrm{a}}}{2 C_{\mathrm{v}}^{\mathrm{a}}}, W_{\mathrm{w}}=\frac{r_{\mathrm{e}}^{2} F_{\mathrm{w}}}{2 C_{\mathrm{v}}^{\mathrm{w}}}$,

$$
A_{\mathrm{w}}=C_{\mathrm{a}} A_{\mathrm{a}}, W_{\mathrm{a}}=C_{\mathrm{w}} W_{\mathrm{w}}, A_{\mathrm{q}}=C_{\mathrm{q}}^{\mathrm{a}} A_{\mathrm{a}}, W_{\mathrm{q}}=C_{\mathrm{q}}^{\mathrm{w}} W_{\mathrm{w}} .
$$

Laplace transform of equations (16) is carried out in the time domain, thus:

$$
\tilde{\bar{u}}_{\mathrm{a}}=A_{\mathrm{a}}\left(s \tilde{\overline{\mathrm{u}}}_{\mathrm{a}}-\bar{u}_{\mathrm{a}}^{0}\right)+A_{\mathrm{w}}\left(s \tilde{\overline{\bar{u}}}_{\mathrm{w}}-\bar{u}_{\mathrm{w}}^{0}\right)-A_{\mathrm{q}}\left(s \tilde{q}-q_{0}\right)+B \tilde{\mathrm{u}}_{\mathrm{w}}
$$

$\tilde{\bar{u}}_{\mathrm{w}}=W_{\mathrm{w}}\left(s \tilde{\bar{u}}_{\mathrm{w}}-\bar{u}_{\mathrm{w}}^{0}\right)+W_{\mathrm{a}}\left(s \tilde{\bar{u}}_{\mathrm{a}}-\bar{u}_{\mathrm{a}}^{0}\right)-W_{\mathrm{q}}\left(s \tilde{q}-q_{0}\right)+B \tilde{u}_{\mathrm{ww}}$

where $\tilde{\bar{u}}_{\mathrm{a}}, \tilde{\bar{u}}_{\mathrm{w}}$ and $\tilde{q}$ are $\bar{u}_{\mathrm{a}}, \bar{u}_{\mathrm{w}}$ and $q(\mathrm{t})$ in the Laplace domain respectively. $\bar{u}_{\mathrm{a}}^{0}, \bar{u}_{\mathrm{w}}^{0}$ and $q_{0}$ are the initial values of $\bar{u}_{\mathrm{a}}, \bar{u}_{\mathrm{w}}$ and $q(\mathrm{t})$, respectively.

By substituting the boundary condition of well resistance in equation (7) into equations (11),

$$
\begin{gathered}
\frac{\partial^{2} u_{\mathrm{aw}}}{\partial z^{2}}=\frac{\left(N^{2}-1\right) k_{\mathrm{a}}}{k_{\mathrm{aw}} C_{\mathrm{v}}^{\mathrm{a}}}\left(-C_{\mathrm{a}} \frac{\partial \bar{u}_{\mathrm{w}}}{\partial t}-\frac{\partial \bar{u}_{\mathrm{a}}}{\partial t}+C_{\mathrm{q}}^{\mathrm{a}} \frac{\partial q}{\partial t}\right) \\
\frac{\partial^{2} u_{\mathrm{ww}}}{\partial z^{2}}=\frac{\left(N^{2}-1\right) k_{\mathrm{w}}}{k_{\mathrm{ww}} C_{\mathrm{v}}^{\mathrm{w}}}\left(-C_{\mathrm{w}} \frac{\partial \bar{u}_{\mathrm{a}}}{\partial t}-\frac{\partial \bar{u}_{\mathrm{w}}}{\partial t}+C_{\mathrm{q}}^{\mathrm{w}} \frac{\partial q}{\partial t}\right)
\end{gathered}
$$


Substituting equation (18) into equation (16) and performing Laplace transform, result in:

$$
\begin{aligned}
& \frac{\mathrm{d}^{2} \tilde{u}_{\mathrm{aw}}}{\mathrm{d} z^{2}}=\rho_{\mathrm{a}}\left(\tilde{\bar{u}}_{\mathrm{a}}-B \tilde{u}_{\mathrm{aw}}\right) \\
& \frac{d^{2} \tilde{u}_{\mathrm{ww}}}{d z^{2}}=\rho_{\mathrm{w}}\left(\tilde{\bar{u}}_{\mathrm{w}}-B \tilde{u}_{\mathrm{ww}}\right)
\end{aligned}
$$

where $G_{\mathrm{a}}$ and $G_{\mathrm{w}}$ is the well resistance factor related to air and water phases, respectively. $\tilde{u}_{\mathrm{aw}}$ and $\tilde{u}_{\mathrm{ww}}$ are the Laplace form of $u_{\mathrm{aw}}$ and $u_{\mathrm{ww}}$, respectively. $G_{\mathrm{a}}=k_{\mathrm{a}} H^{2}\left(4 k_{\mathrm{aw}} r_{\mathrm{w}}^{2}\right)^{-1} \quad, \quad G_{\mathrm{w}}=k_{\mathrm{w}} H^{2}\left(4 k_{\mathrm{ww}} r_{\mathrm{w}}^{2}\right)^{-1}$, $\rho_{\mathrm{a}}=-8\left(N^{2}-1\right) G_{\mathrm{a}}\left(N^{2} H^{2} F_{\mathrm{a}}\right)^{-1}$ $\rho_{\mathrm{w}}=-8\left(N^{2}-1\right) G_{\mathrm{w}}\left(H^{2} N^{2} F_{\mathrm{w}}\right)^{-1}$.

The equations (17) and (19) are combined to obtain:

$$
\begin{aligned}
& \frac{\mathrm{d}^{2} \tilde{u}_{\mathrm{aw}}}{\mathrm{d} z^{2}}=\Omega_{\mathrm{a}} \tilde{u}_{\mathrm{aw}}+\Omega_{\mathrm{w}} \tilde{u}_{\mathrm{ww}}+\Omega_{\mathrm{q}} \\
& \frac{\mathrm{d}^{2} \tilde{u}_{\mathrm{ww}}}{d z^{2}}=\psi_{\mathrm{w}} \tilde{u}_{\mathrm{ww}}+\psi_{\mathrm{a}} \tilde{u}_{\mathrm{aw}}+\psi_{\mathrm{q}}
\end{aligned}
$$

where $\quad D=s^{2} A_{\mathrm{w}} W_{\mathrm{a}}-s^{2} A_{\mathrm{a}} W_{\mathrm{w}}+s A_{\mathrm{a}}+s W_{\mathrm{w}}-1$

$\Omega_{\mathrm{a}}=B \rho_{\mathrm{a}}\left(s W_{\mathrm{w}}-1-D\right) D^{-1}$

$\psi_{\mathrm{w}}=B \rho_{\mathrm{w}}\left(s A_{\mathrm{a}}-1-D\right) D^{-1} \quad, \quad \psi_{a}=-s B W_{a} \rho_{w} D^{-1}$,

$\Omega_{\mathrm{q}}=\rho_{\mathrm{a}} D^{-1}\left[\left(s A_{\mathrm{w}} W_{\mathrm{a}}-s A_{\mathrm{a}} W_{\mathrm{w}}+A_{\mathrm{a}}\right) \bar{u}_{\mathrm{a}}^{0}+A_{\mathrm{w}} \bar{u}_{\mathrm{w}}^{0}+\left(s A_{\mathrm{w}} W_{\mathrm{q}}-s A_{\mathrm{q}} W_{\mathrm{w}}+A_{\mathrm{q}}\right)\left(s \tilde{q}-q_{0}\right)\right]$, $\Omega_{\mathrm{w}}=-s B A_{\mathrm{w}} \rho_{\mathrm{a}} D^{-1}$,

$\psi_{\mathrm{q}}=\rho_{\mathrm{w}} D^{-1}\left[\left(s A_{\mathrm{w}} W_{\mathrm{a}}-s A_{\mathrm{a}} W_{\mathrm{w}}+W_{\mathrm{w}}\right) \bar{u}_{\mathrm{w}}^{0}+W_{\mathrm{a}} \bar{u}_{\mathrm{a}}^{0}+\left(s A_{\mathrm{q}} W_{\mathrm{a}}-s A_{\mathrm{a}} W_{\mathrm{q}}+W_{\mathrm{q}}\right)\left(s \tilde{q}-q_{0}\right)\right]$

The above equations (20) is decoupled by introducing variables $\tilde{\Phi}_{1}$ and $\tilde{\Phi}_{2}$. The details of decoupling method can be referred to Qin et al. [3].

$$
\begin{aligned}
& \frac{\mathrm{d}^{2} \tilde{\Phi}_{1}}{\mathrm{~d} z^{2}}-Q_{1} \tilde{\Phi}_{1}-\left(\Omega_{\mathrm{q}}+\psi_{\mathrm{q}} q_{21}\right)=0 \\
& \frac{\mathrm{d}^{2} \tilde{\Phi}_{2}}{\mathrm{~d} z^{2}}-Q_{2} \tilde{\Phi}_{2}-\left(\Omega_{\mathrm{q}} q_{12}+\psi_{\mathrm{q}}\right)=0
\end{aligned}
$$

where $\quad \tilde{\Phi}_{1}=\tilde{u}_{\mathrm{aw}}+\tilde{u}_{\mathrm{ww}} q_{21} \quad, \quad \tilde{\Phi}_{2}=\tilde{u}_{\mathrm{aw}} q_{12}+\tilde{u}_{\mathrm{ww}}$, $q_{21}=\Omega_{\mathrm{w}} /\left(Q_{1}-\psi_{\mathrm{w}}\right) \quad, \quad q_{12}=\psi_{\mathrm{a}} /\left(Q_{2}-\Omega_{\mathrm{a}}\right)$ $Q_{1,2}=\frac{1}{2}\left[\Omega_{\mathrm{a}}+\psi_{\mathrm{w}} \mp \sqrt{\left(\Omega_{\mathrm{a}}-\psi_{\mathrm{w}}\right)^{2}+4 \Omega_{\mathrm{w}} \psi_{\mathrm{a}}}\right]$.

The boundary conditions in equations (8) and (9) after Laplace transform combined with equations (21) leads to:

$$
\begin{aligned}
& \tilde{\Phi}_{1}=\xi_{1}\left[\cosh \left(H \sqrt{Q_{1}}-z \sqrt{Q_{1}}\right) \operatorname{sech}\left(H \sqrt{Q_{1}}\right)-1\right] \\
& \tilde{\Phi}_{2}=\xi_{2}\left[\cosh \left(H \sqrt{Q_{2}}-z \sqrt{Q_{2}}\right) \operatorname{sech}\left(H \sqrt{Q_{2}}\right)-1\right]
\end{aligned}
$$

where $\xi_{1}=\left(\Omega_{\mathrm{q}}+\psi_{\mathrm{q}} q_{21}\right) / Q_{1}, \xi_{2}=\left(\Omega_{\mathrm{q}} q_{12}+\psi_{\mathrm{q}}\right) / Q_{2}$.

According to the expressions of $\bar{\Phi}_{1}, \bar{\Phi}_{2}$ and equations (19), (22).

$$
\tilde{\bar{u}}_{\mathrm{a}}=\frac{\left(\xi_{1} Q_{1} \lambda_{1}-q_{21} \xi_{2} Q_{2} \lambda_{2}\right)+\rho_{\mathrm{a}} B\left[\xi_{1}\left(\lambda_{1}-1\right)-q_{21} \xi_{2}\left(\lambda_{2}-1\right)\right]}{\rho_{\mathrm{a}}\left(1-q_{12} q_{21}\right)}
$$

$\tilde{\bar{u}}_{\mathrm{w}}=\frac{\left(\xi_{2} Q_{2} \lambda_{2}-q_{12} \xi_{1} Q_{1} \lambda_{1}\right)+\rho_{\mathrm{w}} B\left[\xi_{2}\left(\lambda_{2}-1\right)-q_{12} \xi_{1}\left(\lambda_{1}-1\right)\right]}{\rho_{\mathrm{w}}\left(1-q_{21} q_{12}\right)}$

where $\quad \lambda_{1}=\cosh \left(H \sqrt{Q_{1}}-z \sqrt{Q_{1}}\right) \operatorname{sech}\left(H \sqrt{Q_{1}}\right)$, $\lambda_{2}=\cosh \left(H \sqrt{Q_{2}}-z \sqrt{Q_{2}}\right) \operatorname{sech}\left(H \sqrt{Q_{2}}\right)$.

With the utilization of the numerical inverse Laplace transform by Crump's method and programming process, the general semi-analytical solutions can be obtained. Details of the Crump's method and time-varying loadings can refer to Wang et al. [8] and Xu et al. [9], respectively.

\subsection{Verification}

In order to verify the validity of the presented solution, a ideal case under instantaneous loading, which neglecting the well resistance and smear effect, is compared with the previous solution obtained by Zhou et al. [7] (equal-strain) and Qin et al. [3] (free-strain). The relevant parameters of unsaturated soil VD foundation are as follows:

$H=5 \mathrm{~m}, r_{\mathrm{w}}=0.2 \mathrm{~m}, r_{\mathrm{e}}=1.8 \mathrm{~m}, S_{\mathrm{r} 0}=80 \%, n_{0}=50 \%$, $q_{0}=100 \mathrm{kPa}\left(u_{\mathrm{a}}^{0}=20 \mathrm{kPa}, u_{\mathrm{w}}^{0}=40 \mathrm{kPa}\right), k_{\mathrm{w}}=1 \times 10^{-10} \mathrm{~m} / \mathrm{s}$, $m_{1 \mathrm{k}}^{\mathrm{w}}=-5 \times 10^{-5} \mathrm{kPa}^{-1} \quad, \quad m_{1 \mathrm{k}}^{\mathrm{a}}=-2 \times 10^{-4} \mathrm{kPa}^{-1}$, $m_{2}^{\mathrm{w}}=-2 \times 10^{-4} \mathrm{kPa}^{-1}, m_{2}^{\mathrm{a}}=1 \times 10^{-4} \mathrm{kPa}^{-1}$.
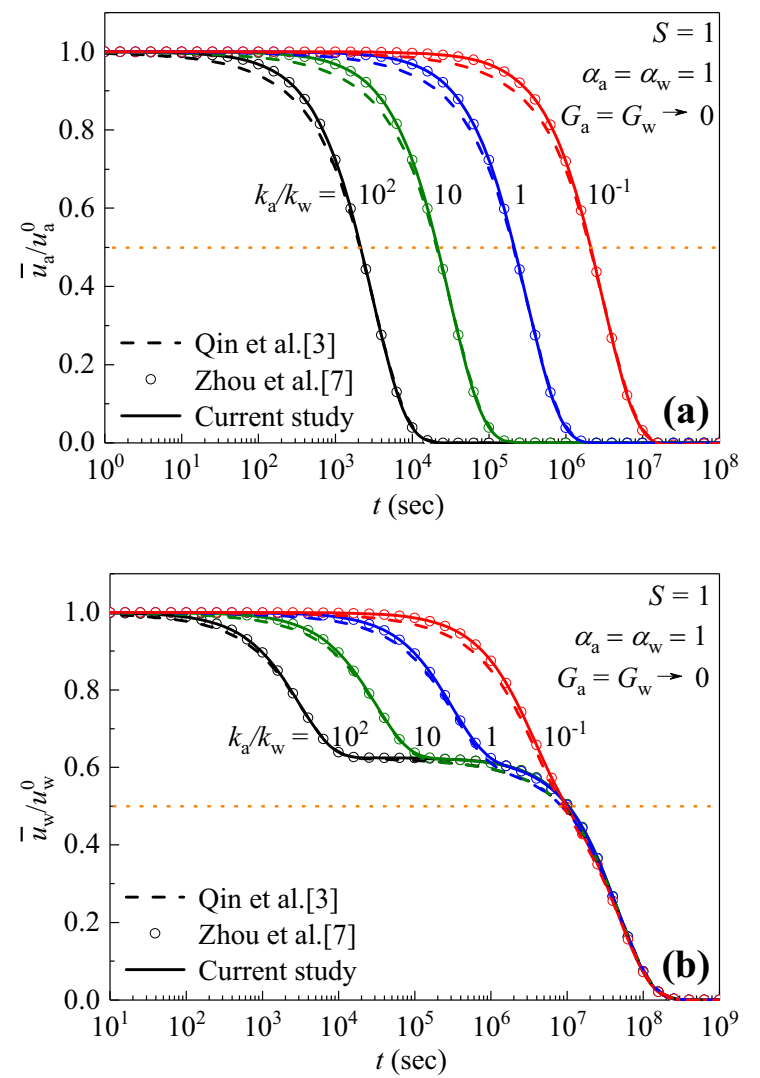

Figure 2. Comparison of the dissipation of excess pore pressures with respect to (a) air and (b) water phases with different values of $k_{\mathrm{a}} / k_{\mathrm{w}}$ under instantaneous loading.

In the assumption of equal-strain and free-strain, the excess pore pressures with respect to air and water phases for the current and previous solution dissipates with time 
under different values of $k_{\mathrm{a}} / k_{\mathrm{w}}$ are shown in figure 2 . The solution in this paper is compared with the solution obtained by Zhou et al. [7] under the assumption of equalstrain, it is found that the dissipation curves of the two methods are almost identical in the consolidation process. On the other hand, the dissipation curves of excess pore pressures on the assumption of free-strain and equal-strain are consistent after more than half of the dissipation. Based on the above comparison, it shows that the proposed solution for equal-strain consolidation aided by VDs to unsaturated soils is valid and reliable.

\section{Case study and discussions}

In the construction process of Preloading Method, the design-preloading is usually applied gradually. As a simplified model of multi-ramp loading, exponential loading is often used to analyse the consolidation characteristics of soil in practical engineering, it can be expressed as:

$$
q(t)=q_{0}+b q_{0}\left(1-e^{-\lambda t}\right)
$$

where $q_{0}$ is the initial surcharge, $b$ and $\lambda$ are the constant and parameter of loading, respectively. $b=1$ and $q_{0}=100$ $\mathrm{kPa}$ are applied in this paper.
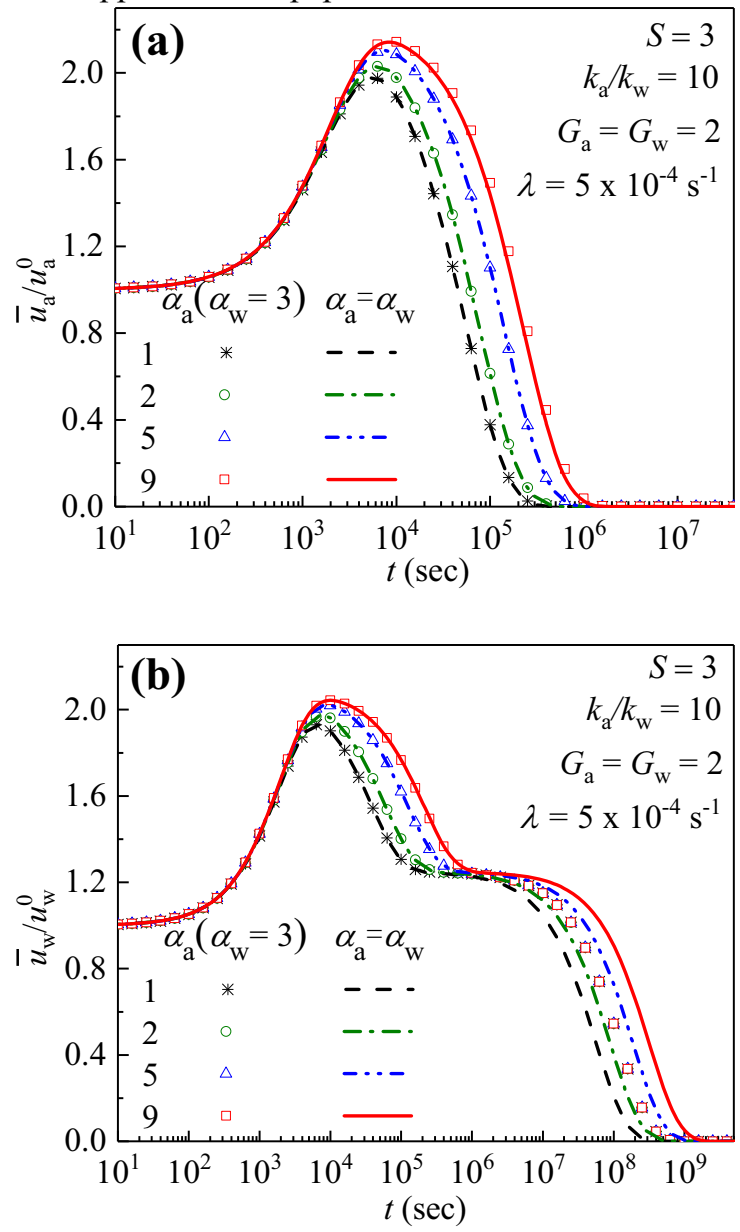

Figure 3. Dissipation curves of excess pore pressure with respect to (a) air and (b) water phases with different smear coefficients $\left(\alpha_{\mathrm{a}}\right.$ and $\left.\alpha_{\mathrm{w}}\right)$ under exponential loading.

Figure 3 shows the dissipation curves of average excess pore pressures in respect of air and water phases with time and different smear coefficients $\left(\alpha_{\mathrm{a}}\right.$ or $\left.\alpha_{\mathrm{w}}\right)$ at $z=0.5 \mathrm{H}$ under exponential loading. Obviously, it can be obtained from figure 3 that the dissipation of excess pore pressures is accelerated with the decrease of smear coefficients $\left(\alpha_{\mathrm{a}}\right.$ or $\left.\alpha_{\mathrm{w}}\right)$. However, at different values of $\alpha_{\mathrm{a}}\left(\alpha_{\mathrm{w}}=3\right)$, the dissipation curves of excess pore-water pressure almost coincide at the latter stage. In addition, by comparing with figure 3(a), it is found that the air phase has completely dissipated at this stage. This shows that, in the process of consolidation for unsaturated soils with VDs, the first and second stages of dissipation to excess pore-water pressure is controlled by the dissipation of air phase and water phase, respectively.

Figure 4(a), (b) presents the effects of well resistance factors (i.e. $G_{\mathrm{a}}, G_{\mathrm{w}}$ ) on the excess pore pressures relating to air and water phases at $z=0.5 \mathrm{H}$ under exponential loading. By comparing the dissipation
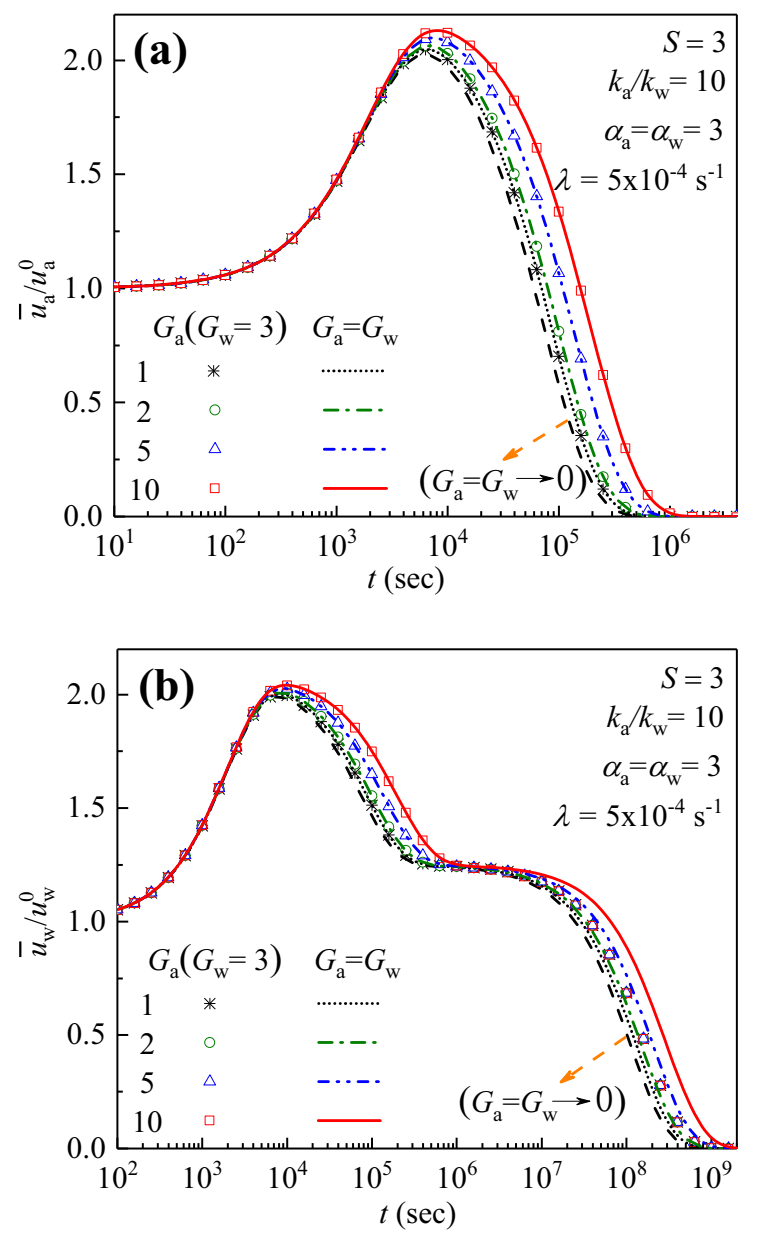

Figure 4. Dissipation curves of excess pore pressures with respect to (a) air and (b) water phases with different well resistance factors $\left(G_{\mathrm{a}}\right.$ and $\left.G_{\mathrm{w}}\right)$ under exponential loading.

curves of excess pore pressures at different well resistance factors with that of neglecting well resistance $\left(G_{\mathrm{a}}=G_{\mathrm{w}} \rightarrow\right.$ $0)$, it can be seen that the well resistance obstructs the consolidation process. And with the increase of well resistance factor, the consolidation time is extended. Moreover, when $G\left(G_{\mathrm{a}}\right.$ or $\left.G_{\mathrm{w}}\right)$ is equal to 1 , the dissipation curves in figure $4(\mathrm{a})$, (b) of excess pore pressures with regard to air and water phases have little difference from those of ignoring well resistance. That is to say, when well 
resistance factor (i.e. $G_{\mathrm{a}}, G_{\mathrm{w}}$ ) is less than 1 , well resistance can be ignored. On the other hand, the dissipation of excess pore-water pressure presented in figure 4(b) is consistent with different $G_{\mathrm{a}}\left(G_{\mathrm{w}}=3\right)$, which is similar to figure 3(b).
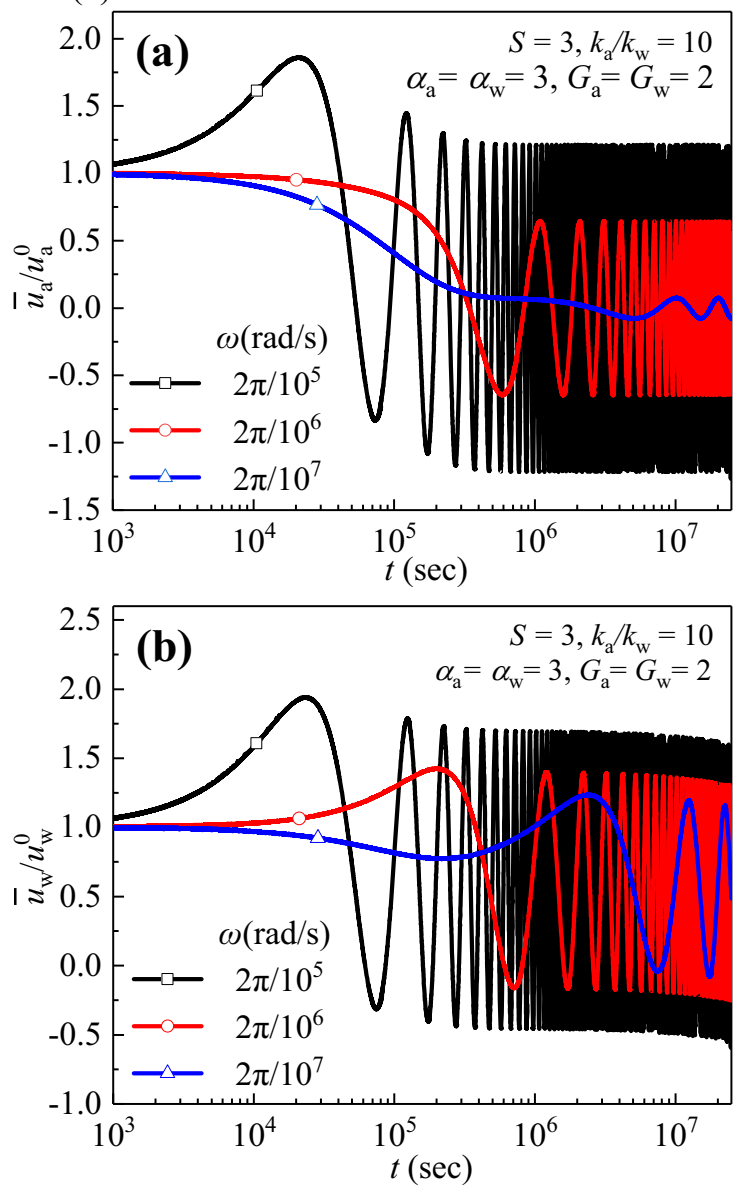

Figure 5. Influence of loading frequency $\omega$ on dissipation of excess pore pressures with respect to (a) air and (b) water phases under sinusoidal cyclic loading

In practical engineering, with the exception of the above instantaneous loading and exponential loading, the unsaturated soil VD foundation is sometimes subjected to cyclic loadings. Such as dynamic stress in subgrade caused by moving loadings on pavement surfaces, and variable gravity stress caused by oil level change in oil depot. Figure 5 analyses the influence of different loading frequency on the dissipation of excess pore pressures for both air and water phases with time under sinusoidal cyclic loading. The cyclic loading applied is $q(t)=100 \sin (\omega t)+100$. It can be observed that a larger value of the loading frequency $\omega$ induces a greater value of the amplitude and less fluctuation period of dissipation rate of excess pore air and water pressures. In addition, the loading frequency has an insignificant influence on the mean values of the dissipation rates of excess pore pressures.

\section{Conclusions}

A general semi-analytical solution of VD-enhanced consolidation to unsaturated soils considering well resistance and smear effect is presented in this paper. The influence of the smear coefficients, well resistance factors and cyclic loading frequency on the dissipation of excess pore pressures relating to air and water phases are analyzed by numerical examples. It can be concluded that the dissipation of excess pore pressures becomes slower with the increase of smear coefficient $\left(\alpha_{\mathrm{a}}\right.$ or $\left.\alpha_{\mathrm{w}}\right)$ or well resistance coefficient $\left(G_{\mathrm{a}}\right.$ or $\left.G_{\mathrm{w}}\right)$. In addition, when the well resistance coefficient is less than 1, the flow resistance of VD material can be ignored. Furthermore, the shorter the cyclic loading period, the larger the amplitude of dissipation rate and the smaller the fluctuation period. What's more, the general semi-analytical solutions can be utilized to analyze the consolidation problem with more complex loadings in practical engineering.

\section{Acknowledgement}

This study was sponsored by the National Natural Science Foundation of China (Grant No.41372279).

\section{References}

1. Fredlund, D.G., Hasan, J.U. (1979) One-dimensional consolidation theory: unsaturated soils. J. Can Geotech J., 17: 521-31.

2. Qin, A.F., Sun, D.A, Tan Y.W. (2010) Semi analytical solution for one-dimensional consolidation of unsaturated soils. J. Applied mathematics and mechanics. 31(2): 199-209. (in Chinese)

3. Qin, A.F., Sun, D.A., Yang L.P., et al. (2010) A semianalytical solution to consolidation of unsaturated soils with the free drainage well. J. Computers and Geotechnics, 37(7): 867-875.

4. Zhou, W.H., Tu S. (2012) Unsaturated consolidation in a sand drain foundation by differential quadrature method. J. Procedia Earth \& Planetary Science, 5(8): 52-57.

5. Ho, L., Fatahi, B., (2016) Axisymmetric consolidation in unsaturated soil deposit subjected to time-dependent loadings. J. International Journal of Geomechanics. 17(2), 04016046.

6. Ho, L., Fatahi, B. (2018) Analytical solution to axisymmetric consolidation of unsaturated soil stratum under equal strain condition incorporating smear effects. J. Numerical and Analytical Methods in Geomechanics. 42(15): 1890-1913.

7. Zhou, F., Chen, Z., Wang, X. (2018). An equal-strain analytical solution for the radial consolidation of unsaturated soils by vertical drains considering drain resistance. J. Advances in Civil Engineering, 2018.

8. Wang, L., Sun, D.A., Qin, A.F. (2017) General semianalytical solutions to one-dimensional consolidation for unsaturated soils. J. Applied Mathematics and Mechanics (English Edition), 38 (6): 831-850.

9. Xu, C.-J., Chen, Q.-Z., Liang, L.-J., et al. (2017) Analysis of consolidation of a soil layer with depth- 
dependent parameters under time-dependent loadings. J. European Journal of Environmental and Civil Engineering. 22(sup1), s200-s212. 